\title{
Effect of Chronic Alcohol Consumption on Phosphatidylcholine Hydroperoxide Content of Rat Liver and Brain
}

\author{
Chang-Won Pyun ${ }^{1}$, Prabhat Kuar Mandal ${ }^{2}$, Go-Eun Hong ${ }^{1}$ and Chi-Ho Lee ${ }^{3 *}$ \\ ${ }^{1}$ Department of Food Science and Biotechnology of Animal Resources, Konkuk University, Seoul, 147-701, South Korea, \\ ${ }^{2}$ Department of Livestock Products Technology, Rajiv Gandhi Institute of Veterinary Education and Research, Pondicherry 605 \\ 009, India, ${ }^{3}$ Animal Resources Research Center, Konkuk University, Seoul, 143-701, South Korea
}

*For correspondence: Email: leech@konkuk.ac.kr; Tel: +82-2-450-3681; Fax: +82-2-453-1948

\begin{abstract}
Purpose: To investigate the correlation between alcohol-induced oxidative stress and tissue phosphatidylcholine hydroperoxide $(\mathrm{PC}-\mathrm{OOH})$ content of rat liver and brain.

Methods: Ten Wistar rats were divided into two groups: one group was given $20 \%$ ethanol (5 g/kg) and the other the same volume of normal saline, orally once a day for 6 weeks. Catalase activity, malondialdehyde (MDA) content, total antioxidant capacity (TAC) and PC-OOH content of liver and brain were determined.

Results: The ethanol-treated group had lower catalase activity and total antioxidant capacity. MDA level in the liver was $0.33 \pm 0.07 \mu \mathrm{M} / \mathrm{mg}$ protein which is significantly $(p<0.05)$ higher than that of the control group $(0.17 \pm 0.06 \mu \mathrm{M} / \mathrm{mg}$ protein), but in brain, there was no significant difference. $\mathrm{PC}-\mathrm{OOH}$ level in the ethanol-treated group was $46.91 \pm 12.87 \mathrm{pmol} / \mathrm{mg}$ in liver and $71.97 \pm 26.12 \mathrm{pmol} / \mathrm{mg}$ protein in brain while $\mathrm{PC}-\mathrm{OOH}$ level of control group was $21.40 \pm 10.71 \mathrm{pmol} / \mathrm{mg}$ protein in liver and that in brain was $25.29 \pm 5.67 \mathrm{pmol} / \mathrm{mg}$ protein pmol. Thus, $\mathrm{PC}-\mathrm{OOH}$ levels in both liver and brain were significantly $(p<0.05)$ higher than that of control group. $\mathrm{PC}-\mathrm{OOH}$ content in the liver and brain correlated significantly $(p<0.05)$ with catalase activity and total antioxidant capacity $(T A C)$.

Conclusion: The study demonstrates that $\mathrm{PC}-\mathrm{OOH}$ content in liver and brain tissues may be a marker for alcohol-induced oxidative stress.
\end{abstract}

Keywords: Alcohal toxicity, Oxidative stress, Phosphatidylcholine hydroperoxide, Liver, Brain, Biomarker

Tropical Journal of Pharmaceutical Research is indexed by Science Citation Index (SciSearch), Scopus, International Pharmaceutical Abstract, Chemical Abstracts, Embase, Index Copernicus, EBSCO, African Index Medicus, JournalSeek, Journal Citation Reports/Science Edition, Directory of Open Access Journals (DOAJ), African Journal Online, Bioline International, Open-J-Gate and Pharmacy Abstracts

\section{INTRODUCTION}

Alcohol is consumed worldwide as a drink by humans. Regular and unlimited use of alcohol leads to toxicity and alcohol-induced pathological problems and can constitute a menace in the society. Therefore, several studies have focused on the mechanism of cell or tissue injury caused by alcohol-induced oxidative stress and protective methods. Alcohol-induced oxidative stress leads to various diseases like hepatic diseases, cardiovascular diseases, and nervous diseases [1-3]. The role of reduced nicotinamide adenine denucleotide (NADH) is one of the more reliable hypotheses of ethanol-induced oxidative stress. The increased level of $\mathrm{NADH}$, during metabolizing ethanol, leads to increase respiratory rate and the absorption of oxygen is increased. Eventually, the production of reactive oxygen species are elevated [4]. Another reliable 
hypothesis is the increased activity of cytochrome P450 2E1 (CYP2E1) by ethanol consumption. Previous studies reported that increased level of CYP2E1 activity is related to the production of ROS [5].

The common methods for measuring the effect of oxidative stress are determination of the level of malondialdehyde (MDA), reactive oxygen species (ROS), glutathione (GSSG/GSH) or measuring the activity of antioxidant enzyme [69]. In addition, protein carbonyl content in the tissue samples is also used for tissue injury [10].

Phosphatidylcholine (PC) and phosphatidylethanolamine $(P E)$, which are the main composition of cell wall are oxidized by oxidative stress-induced tissue injury and remains in the tissue or flow in the plasma. Miyazawa et al developed the method for simultaneous determination of $\mathrm{PC}-\mathrm{OOH}$ and $\mathrm{PE}-\mathrm{OOH}$ by using the chemiluminescence analyzer-high performance liquid chromatography (CL-HPLC) system [11].

The aim of this study was to investigate the correlation between the alcohol-induced oxidative stress and $\mathrm{PC}-\mathrm{OOH}$ content in rat liver and brain.

\section{EXPERIMENTAL}

\section{Animal studies}

Ten male Wistar rats ( 7 weeks old, mean body weight approx $150 \mathrm{~g}$ ) were purchased from the Central Laboratory Animal Inc (Seoul, Korea) and allowed a normal diet for one week while adapting to the new raising environment. After the adaptation period, rats were divided in two groups. One group was treated with $20 \%$ ethanol (5 $\mathrm{g}$ ethanol/kg body weight) and the other group was treated with the same volume of $8.5 \%$ saline solution, via oral administration by using the gavage feeding needle once a day. High fat diet (45\% of energy divided from fat) and water were administered by ad libitum feeding. After 6 weeks, rats were fasted for $24 \mathrm{~h}$ and anesthetized with intraperitoneal injection of Zoletil (Zoletil 50, Virbac, Carros, France), blood was collected from the abdominal aorta, and the liver and brain were extracted for measuring antioxidant capacity and PC-OOH levels.

All experimental protocols and schedules involving animals were approved (ref no. KU11101) by Institutional Animal Care and Use Committee of Konkuk University and the international guideline for the care and use of laboratory animals was followed [12].

\section{Organ weight}

The main organs (liver, kidney, spleen, adipose tissues, and brain) were removed, rinsed twice with phosphate buffered saline solution (PBS), and dried with filter paper. Their weights were measured immediately using electronic balance (AR2140, Ohaus, Pine Brook, NJ). Organ weight, except that of brain, was presented as organ-tobody weight ratio.

\section{Determination of malondialdehyde}

The level of malondialdehyde (MDA) was determined by using MDA quantitation TBARS assay kit (Cell Biolabs, San Diego, CA). The tissue sample was homogenized on ice with BHT containing $1 \mathrm{X}$ phosphate buffered saline (1X PBS) solution. The homogenate was centrifuged at $10,000 \mathrm{~g}$ for $5 \mathrm{~min}$ to collect the supernatant. A $100 \mu \mathrm{L}$ of tissue lysate or MDA standard were moved on microcentrifuge tubes. A $100 \mu \mathrm{L}$ of Sodium dodecyl sulfate (SDS) lysis solution (150 $\mathrm{mM}$ of $\mathrm{NaCl}$ and $0.1 \mathrm{mM}$ of EDTA in $10 \mathrm{mM}$ Trisbuffer, $\mathrm{pH}$ 7.5) was added and mixed, and then, a $250 \mu \mathrm{L}$ of 2-thiobarbituric acid (TBA) reagent was added and incubated at $95{ }^{\circ} \mathrm{C}$ for $60 \mathrm{~min}$. The absorbance of the reactant was read at 532 $\mathrm{nm}$. MDA content was expressed as $\mathrm{nmol}$ $\mathrm{MDA} / \mathrm{mg}$ protein. Protein content of the tissue was determined by the biuret method.

\section{Evaluation of antioxidative enzyme activity and total antioxidant capacity}

The catalase activity (Cell Biolabs, San Diego, $\mathrm{CA}$ ), superoxide dismutase activity (Cell Biolabs, San Diego, CA), and total antioxidant capacity (BioAssay Systems, Hayward, CA) was determined by using a colorimetric assay kit. The liver and brain tissues were homogenized with 1X phosphate buffered saline (1X PBS) solution. The homogenate was centrifuged at $10,000 \times \mathrm{g}$ for $15 \mathrm{~min}$ at $4{ }^{\circ} \mathrm{C}$. The supernatant was collected and stored at $-80^{\circ} \mathrm{C}$ before the assay.

\section{Determination of PC-OOH}

The photoirradiation method for preparation of the $\mathrm{PC}-\mathrm{OOH}$ standard was used [11]. The amount of peroxide in the standard solution was determined by the method of the American Oil Chemist's Society [13]. The hydroperoxide concentration of the photo-oxidized PC was 19.1 $\mu \mathrm{mol}$ hydroperoxide- $\mathrm{O}_{2} / \mathrm{g}$ of $\mathrm{PC}$. Total lipids of the liver and brain tissue were extracted by using a modification of the method of Folch et al [14]. The standard solution and lipid extract of the tissue were determined by using chemiluminescence analyzer-high performance 
liquid chromatography (CL-HPLC) system [11]. The detail condition of CL-HPLC is shown in Table 1. $\mathrm{PC}-\mathrm{OOH}$ content was expressed as $\mathrm{mg} / \mathrm{g}$ tissue protein. The total protein of liver and brain was determined by biuret method [14].

\section{Statistical analysis}

All data are presented as the mean \pm standard error of the mean (S. E. M.). The differences between the groups were calculated by the Duncan's multiple range test $(p<0.05)$. The Pearson's correlation efficiency between the PC$\mathrm{OOH}$ level and other antioxidant capacity was calculated, and $p$-value was calculated for statistical hypothesis testing $(p<0.05)$. All statistical analyses were performed using the Statistical Analysis Software (Statistics Analytical System Institute, Cary, NC, 1988).

\section{RESULTS}

\section{Food intake, body weight and organ weight}

Daily food intake and changes in body weight are shown in Table 2. The food intake and bodyweight gain of the ethanol-treated group was significantly $(p<0.05)$ less than that of the control group. Weights of perirenal (PAT) and epididymal adipose tissue (EAT) decreased remarkably in alcohol treated rats.

\section{Level of malondiadehyde in liver and brain}

The level of hepatic MDA significantly $(p<0.05)$ increased in alcohol treated rats which is in similar pattern as observed in previous study [5]. In liver samples, MDA level of ethanol treated group $(0.33 \pm 0.07 \mu \mathrm{M} / \mathrm{mg})$ was significantly higher than that of control group $(0.17 \pm 0.06$ $\mu \mathrm{M} / \mathrm{mg}$ ).

However, in the brain samples, there were no significant differences in the level of MDA between control $(0.05 \pm 0.02 \mu \mathrm{M} / \mathrm{mg})$ and ethanol treated group $(0.11 \pm 0.05 \mu \mathrm{M} / \mathrm{mg})$. The previous study has reported that alcohol consumption affects the MDA level of particular part in rat brain [16]. They reported that only the cerebellum MDA level was affected by alcohol consumption, while the hippocampus and cortex were not affected.

Table 1: Chemiluminescence analyzer-high performance liquid chromatography conditions for phosphatidylcholine hydroperoxide determination

\begin{tabular}{|c|c|}
\hline Column & ZORBAX NH2 (4.6 × 250 mm, $5 \mu \mathrm{m}$, Agilent Technologies, USA) column \\
\hline Mobile phase & 2-propanol-methanol-water (1350:450:200, v/v/v), flow rate: $1 \mathrm{~mL} / \mathrm{min}$. \\
\hline $\begin{array}{l}\text { Chemiluminescence } \\
\text { analyzer }\end{array}$ & $\begin{array}{l}\text { CLD-1100 (Tohoku Electronic Industries Co., Sendai, Japan) } \\
\text { Reaction temperature: } 40^{\circ} \mathrm{C}\end{array}$ \\
\hline Luminescence reagent & $\begin{array}{l}10 \mathrm{mg} / \mathrm{L} \text { of cytochrome c (from bovine heart, Sigma-Aldrich) and } \\
2 \mathrm{mg} / \mathrm{L} \text { of luminol (Wako pure chemical) in } 50 \mathrm{mM} \text { borate buffer ( } \mathrm{pH} 10.0) \text {. flow rate: } \\
0.8 \mathrm{~mL} / \mathrm{min}\end{array}$ \\
\hline
\end{tabular}

Table 2: Daily food intake, body weight and organ weight of control and treated rats

\begin{tabular}{lcc}
\hline Parameter & Control & Treatment \\
\hline Daily food intake (gram/day) & $17.4 \pm 1.4$ & $13.7 \pm 3.6^{*}$ \\
Initial body weight $(\mathrm{g})$ & $296.2 \pm 9.4$ & $299.6 \pm 7.2$ \\
Final body weight $(\mathrm{g})$ & $464.8 \pm 24.8$ & $415.6 \pm 16.2^{*}$ \\
Change in body weight (\%) & 56.9 & 38.7 \\
Liver (g/kg body weight) & $23.1 \pm 3.2$ & $21.9 \pm 2.0$ \\
Spleen (g/kg body weight) & $1.16 \pm 0.12$ & $1.18 \pm 0.06$ \\
Kidney (g/kg body weight) & $4.86 \pm 0.52$ & $5.03 \pm 0.20$ \\
EAT (g/kg body weight) & $22.3 \pm 5.5$ & $14.3 \pm 0.8^{*}$ \\
PAT (g/kg body weight) & $30.8 \pm 4.9$ & $11.7 \pm 2.3^{*}$ \\
Brain (g) & $1.97 \pm 0.03$ & $1.89 \pm 0.05$ \\
\hline
\end{tabular}

Each value is mean \pm SEM; Control: high fat diet (45\% of calories derived from fat) + saline solution (0.85\% $\mathrm{NaCl})$; Treatment: high fat diet + ethanol (20\%) @ $5 \mathrm{~g} / \mathrm{kg}$ body weight; *Significantly different $(p<0.05) ; E A T$; epididymal adipose tissue, PAT; perirenal adipose tissue 
Activity of antioxidant enzymes and total antioxidant capacity

Total antioxidant capacity (TAC) and the activity of antioxidative enzymes in the rat liver and brain were decreased $(p<0.05)$ in alcohol treated rats (Table 3). This result suggests that the enzymatic antioxidant system has been broken down by ethanol consumption, as previously estimated [18].

\section{$\mathrm{PC}-\mathrm{OOH}$ content of tissue}

The PC-OOH level of control group was $21.40 \pm$ $10.71 \mathrm{pmol} / \mathrm{mg}$ in liver and $25.29 \pm 5.67 \mathrm{pmol} / \mathrm{mg}$ in brain. Ethanol treated rats shows significantly $(p<0.05)$ higher level in both liver $(46.91 \pm 12.87$ $\mathrm{pmol} / \mathrm{mg})$ and brain $(71.97 \pm 26.12 \mathrm{pmol} / \mathrm{mg}$ in brain). This result confirms the fact that alcoholinduced oxidative stress by chronic ethanol consumption may accelerate the tissue injury of the liver and brain. The correlation between PC$\mathrm{OOH}$ content and other oxidative indices was shown in Table 4.

\section{DISCUSSION}

The weights of perirenal (PAT) and epididymal adipose tissue (EAT) decreased remarkably in alcohol treated rats. These results show the similar pattern of decreased body weight caused by the prevention of decline in the plasma leptin, which was induced by the ethanol consumption as reported by the previous study [16]. These results show the similar pattern of decreased body weight caused by the prevention of decline in the plasma leptin, which was induced by the ethanol consumption as reported by the previous study [16].

The increased level of hepatic MDA in alcohol treated rats is in similar pattern as observed in previous study [5]. However, in the brain samples no difference in the level of MDA between control and treated group was observed. A previous study has reported that alcohol consumption affects the MDA level of particular part in rat brain [16]. They reported that only the cerebellum MDA level was affected by alcohol consumption, while the hippocampus and cortex were not affected.

The decreased total antioxidant capacity (TAC) and the activity of antioxidant enzymes in rat liver and brain in alcohol treated rat suggests that the enzymatic antioxidant system may have been broken down by ethanol consumption, which is in agreement with the earlier report [16]. The results in the present study indicate that the ethanol treated rats were sufficiently exposed to alcohol-induced oxidative stress.

The higher levels of $\mathrm{PC}-\mathrm{OOH}$ contents in liver and brain of the alcohol treated rats compared to control group confirms the fact that alcoholinduced oxidative stress by chronic ethanol consumption may accelerate the tissue injury of the liver and brain. All data were statistically correlated with $\mathrm{PC}-\mathrm{OOH}$ content, except the MDA level in the brain. $\mathrm{PC}-\mathrm{OOH}$ contents in both of the liver and brain were increased by the

Table 3: The effect of ethanol on the activity of catalase, total antioxidant capacity (TAC) and total glutathione in rat liver and brain

\begin{tabular}{lcccc}
\hline Parameter & \multicolumn{2}{c}{ Control } & \multicolumn{2}{c}{ Treated } \\
\cline { 2 - 5 } & Liver & Brain & Liver & Brain \\
\hline Catalase activity (U/mg protein) & $27.94 \pm 0.61$ & $21.66 \pm 0.79$ & $17.27 \pm 1.17^{*}$ & $11.79 \pm 1.17^{*}$ \\
SOD activity (inhibition \%/mg protein) & $3.21 \pm 0.17$ & $2.68 \pm 0.13$ & $1.72 \pm 0.18^{*}$ & $1.34 \pm 0.36^{*}$ \\
TAC ( $\mu \mathrm{M}$ trolox equivalents) & $504.9 \pm 17.66$ & $470.3 \pm 31.52$ & $253.7 \pm 15.19^{*}$ & $309.3 \pm 43.96^{*}$ \\
\hline
\end{tabular}

Each value is mean \pm S. E. M; Control: high fat diet (45\% of calories derived from fat) + saline solution (0.85\% $\mathrm{NaCl})$; Treatment: high fat diet + ethanol $(20 \% \mathrm{EtOH}$, @5 g/kg body weight); *significantly different $(p<0.05)$

Table 4: Pearson's correlation coefficient between PC-OOH content in tissue and oxidant markers

\begin{tabular}{lcc}
\hline \multirow{2}{*}{ Oxidant marker } & \multicolumn{2}{c}{ Pearson's correlation efficiency } \\
\cline { 2 - 3 } & Liver $\mathbf{P C}-\mathbf{O O H}$ & Brain PCOOH level \\
\hline MDA & 0.749 & $0.621^{\mathrm{NC}}$ \\
Catalase activity & $-0.912^{*}$ & $-0.924^{*}$ \\
SOD activity & -0.759 & $-0.893^{*}$ \\
(Inhibition \%) & -0.679 & -0.669 \\
Total antioxidant capacity &
\end{tabular}

${ }^{*} P<0.05(n=10) ;{ }^{N C}$ no statistical correlation between each crossed data 

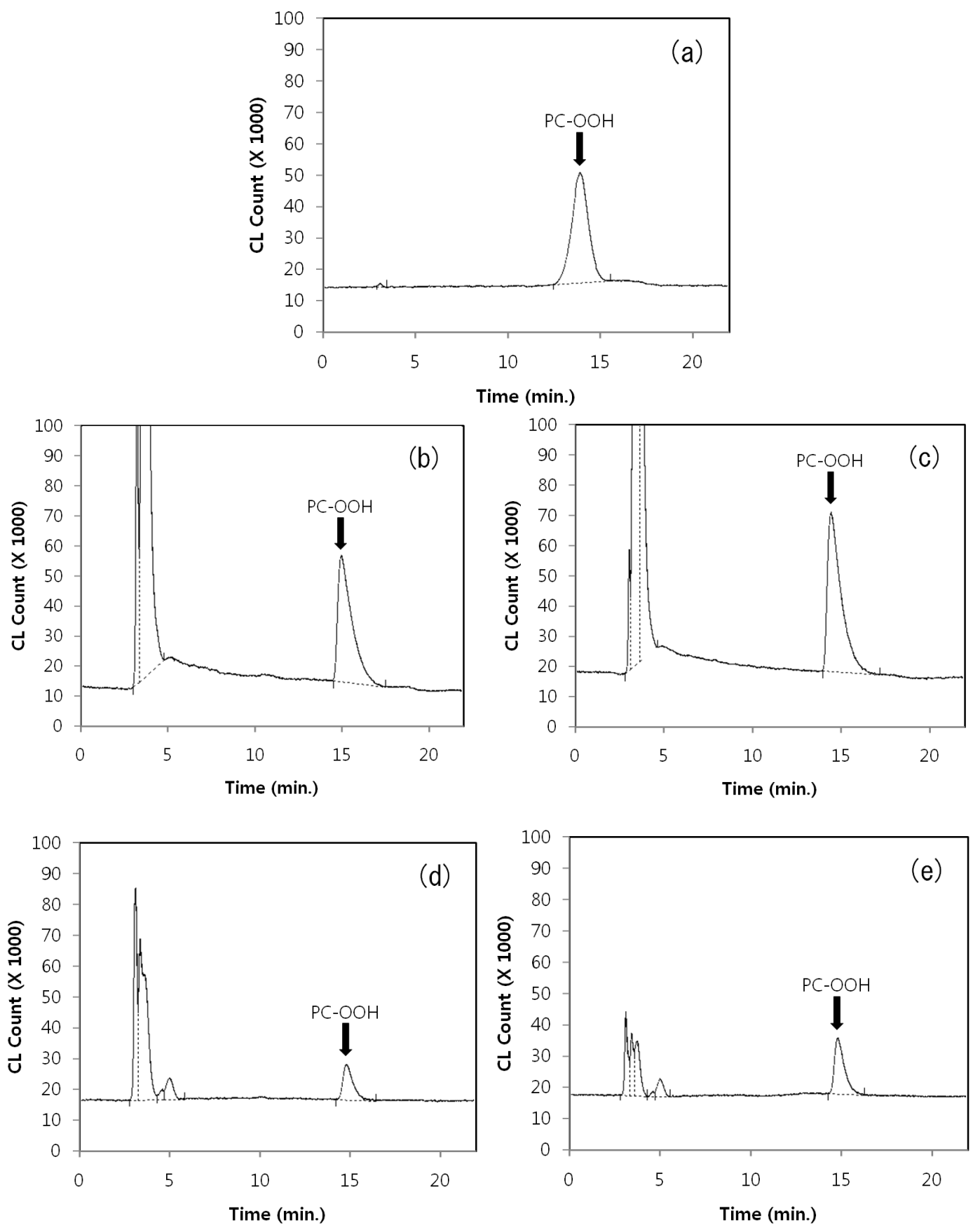

Fig 1: Typical chromatograms of $\mathrm{PC}-\mathrm{OOH}$ in rat liver. (a) $\mathrm{PC}-\mathrm{OOH}$ standard, (b) lipid extract of saline solution treated rat liver, (c) alcohol treated rat liver, (d) saline solution treated rat brain, and (e) alcohol treated rat brain

ethanol treatment. The present study has demonstrated that $\mathrm{PC}-\mathrm{OOH}$ content in the tissue as a new marker for alcohol-induced oxidative stress.

The positive correlation between $\mathrm{PC}-\mathrm{OOH}$ content and other oxidative index in both of the liver and brain has demonstrated that $\mathrm{PC}-\mathrm{OOH}$ content in the tissue as a new marker for alcoholinduced oxidative stress.
Since the method of determination $\mathrm{PC}-\mathrm{OOH}$ has improved, there are several reports about the relationship between oxidative stress-induced diseases and $\mathrm{PC}-\mathrm{OOH}$ content in tissues or blood. Since metabolism of ethanol accelerates the formation of oxidative stress, some studies have been carried out to ascertain the relationship between them. Adachi et al [11] has reported that blood $\mathrm{PC}-\mathrm{OOH}$ level is suitable as a new marker of alcoholic diseases. 
Based on these theories, the current study investigated the relationship between alcohol induced-oxidative stress and tissue $\mathrm{PC}-\mathrm{OOH}$ content. These indices were statistically correlated and $\mathrm{PC}-\mathrm{OOH}$ content showed more sensitive differences between control and alcohol treated group. Therefore, $\mathrm{PC}-\mathrm{OOH}$ content in tissue samples will be a more sensitive and effective index for in vivo alcohol-induced oxidative stress related research in future.

\section{CONCLUSION}

The findings of this study show that the $\mathrm{PC}-\mathrm{OOH}$ content liver and brain tissues may be useful as a marker for alcohol-induced oxidative stress or tissue degradation, and may be a more accurate marker than MDA content in alcohol-related studies. Further studies are, however, required to compare tissue $\mathrm{PC}-\mathrm{OOH}$ content as a marker with protein oxidation (carbonated protein), in addition to histological and immunological investigations.

\section{ACKNOWLEDGEMENT}

This work was supported by Konkuk University in 2013.

\section{REFERENCES}

1. Lieber CS. Liver adaptation and injury in alcoholism. New England J Med 1973; 288: 356-362.

2. Alexander CS. Alcohol and the heart. Annals Int Med 1967; 67: 670-674

3. Hodges DL, Kumar VN, Redford JB. Effects of alcohol on bone, muscle and nerve. American Family Physician 1986; 34: 149-156.

4. Halliwell B. Antioxidant defense mechanisms: from the beginning to the end. Free Rad Res 1999; 31: 261272.

5. French SW, Wong $K$, Jui L, E Albano, Hagbjork AL, Ingelman-Sundberg $M$. Effect of ethanol on cytochrome P450 2E1 (CYP2E1), lipid peroxidation, and serum protein adduct formation in relation to liver pathology pathogenesis. Exptal Mol Path 1993; 58: 61-75.
6. Valenzuela A. The biological significance of malondialdehyde determination in the assessment of tissue oxidative stress. Life Sci 1991; 48: 301-309.

7. Uday B, Dipak $D$, Ranajit KB. Reactive oxygen species: Oxidative damage and pathogenesis. Current Sci 1999; 77: 658-666.

8. Schafer FQ, Buettner GR. Redox environment of the cell as viewed through the redox state of the glutathione disulfide/glutathione couple. Free Radical Biol Med 2001; 30: 1191-1212.

9. Cohen JA, Kaplan MM. The SGOT/SGPT ratio - an indicator of alcoholic liver disease. Digestive Diseases Sci 1979; 24: 835-838.

10. Dalle-Donne I, Rossi R, Giustarini D, Milzani A, Colombo $R$. Protein carbonyl groups as biomarkers of oxidative stress. Clinica Chimica Acta 2003; 329: 23-38.

11. Miyazawa $T$, Suzuki $T$, Fujimoto $K$, Yasuda $K$. Chemiluminescenct simultaneous determination of phosphatidylcholine hydroperoxide and phosphatidylethanolamine hydroperoxide in the liver and brain of the rat. J Lipid Res 1992; 33: 1051-1059.

12. Korean Association for Laboratory Animal Science. Guidelines for Laboratory Animals Management. 2010.

13. Folch J, Lees M, Sloane-Stanley GH. A simple method for the isolation and purification of total lipids from animal tissues. J Biol Chem 1957; 226: 497-509.

14. Gornall AG, Bardawill CJ, David MM. Determination of serum proteins by means of the biuret reaction. J Biol Chem 1949; 177: 751-766.

15. Štrbák VJ, Benický L, Macho D, Jeẑová, Nikodémová M. Four-week ethanol intake decreases food intake and body weight but does not affect plasma leptin, corticosterone, and insulin levels in pubertal rats. Metabolism 1998; 47: 1269-1273.

16. Smith AM, Zeve DR, Grisel JJ, Chen WA. Neonatal alcohol exposure increases malondialdehyde (MDA) and glutathione (GSH) levels in the developing cerebellum. Dev Brain Res 2005; 160: 231-238.

17. Balasubramaniyan V, Kalaivani SJ, Nalini N. Role of leptin on alcohol-induced oxidative stress in Swiss mice. Pharmacol Res 2003; 47: 211-216.

18. Montoliu C, Vallés S, Renau-Piqueras J, Guerri C. Ethanol-induced oxygen radical formation and lipid peroxidation in rat brain: effect of chronic alcohol consumption. J Neurochem 1994; 63: 1855-1862. 